\title{
The Relationship between Cultural Identity, Intrinsic Motivation and Pronunciation Knowledge of Iranian EFL Learners
}

\author{
Somayyeh Shabani (Corresponding author) \\ Islamic Azad University, Tabriz Branch, Iran \\ E-mail: Mahsashabani@Yahoo.com \\ Iman Alipoor \\ Islamic Azad University, Torbat-e-Heydarieh Branch, Iran
}

Received: 21-04-2017

doi:10.7575/aiac.ijels.v.5n.2p.61
Accepted: 29-04-2017

Published: 30-04-2017

\begin{abstract}
Gardener's (1985) socio-cultural model shows that culture is among the variables that can affect learning languages. In addition, a series of studies were prompted by Dörnyie (2005) to gauge the effect of motivation on language learning. This correlational study endeavored to find out any possible interaction between these variables, i.e., cultural identity, intrinsic motivation, and pronunciation knowledge of Iranian EFL learners at intermediate level. To this end, 9 items from Mathews' Cultural Identity Questionnaire (2007) (as cited in Bazrafshan, 2015) along with intrinsic/extrinsic motivation questionnaire developed by Noels, Pelletier, Clement, and Vallerand (2000) were given to the 49 intermediate Iranian EFL learners who were selected among 74 learners studying at Mahan Language Institute in Birjand. The participants' pronunciation knowledge was also measured through an interview. The results of the data analysis through Pearson correlation revealed that cultural identity shows no relationship with pronunciation knowledge of the participants, whereas more intrinsically motivated language learners gained higher scores on the pronunciation test. Pedagogical implications are discussed.
\end{abstract}

Keywords: Cultural identity, Intrinsic motivation, Pronunciation learning, Iranian EFL contexts

\section{Introduction}

Pronunciation is one of the core components of successful communication and a benchmark to test how successfully language learners have acquired the language. It is one of the 5 aspects in the speaking section of IELTS language proficiency tests (Ansarian, Adlipour, Akhavan \& Shafiei, 2016), and a vital part of the speaking skill (Fraser, 2000). In addition, it is a measure of how native-like one's accent in the second language is (Birdsong, 1999). Accurate pronunciation is a factor affecting comprehension in the second language. EFL learners with accurate pronunciation are understood, even if their grammar is impaired, whereas EFL learners with inaccurate pronunciation are often misunderstood (Gilakjani \& Pour Hosein, 2012).

The significance of pronunciation in SLA has been an impetus to conduct research on how ESL/EFL learners' pronunciation could be enhanced. The results of such studies by some scholars linked learning of pronunciation to age (Lightbown \& Spada, 2003) stating that younger learners have a higher chance of acquiring native-like pronunciation. Other studies by Smit (2002), and Dörnyie (2005) linked pronunciation learning to motivation; and believing that the higher language learners level of motivation, the more accurately they learn the pronunciation of the second language. Indeed, there is widespread empirical research supporting the idea that motivation is a crucial factor in SLA (Lim, 2002) which makes it a subject worthy of investigation, however, few studies, if any, have dealt with pronunciation learning and intrinsic motivation of Iranian EFL learners.

Still, another significant, yet often neglected, factor which affects SLA is EFL learners' culture and identity (Norton, 2000). Learning a new language requires language learners to absorb the new culture (Spackman, 2009); however, language learners have their own culture and identity which might come in contrast with the target language culture. A good example of how one's culture can affect one's learning the new language is whether or not the language learners' families put pressure on the youngsters to learn the language. In addition, previous studies have revealed that using culturally bound materials in language classes can foster comprehension (Davoudi \& Ramezani, 2014). Yet, this issue has not been attended to sufficiently. Therefore, the main purpose of the study is to delve into the relationship between cultural identity, intrinsic motivation and pronunciation learning of Iranian EFL learners.

This study focuses on an often neglected type of motivation in the EFL context of Iran-intrinsic motivation. Thus, not only can this study provide the readership with information on motivation and its effect on learning the foreign 
language through the literature review, but also it familiarizes the readers with intrinsic motivation and its correlation with pronunciation knowledge of the language learners.

As the aforementioned variables play a crucial role in SLA and are different from one language learning context to another; due to the differences in the culture and motivation, the current study was carried out.

\subsection{Problem Statement}

Prior research in the field has found significant relationships between motivation and language learning (Dörnyei, 1994 , 2005; Ellis, 2008; Gonzales, 2010). However, Williams and Burden (1997) stated that motivation is a culturally-bound issue and subject to change from one society to another. This may imply that one cannot generalize the findings of other studies in terms of motivation to other contexts unless the studies are replicated and reapproved. Regarding the EFL context of Iran, no prior study was found to deal with pronunciation learning and intrinsic motivation of the language learners. On the other hand, the type of motivation under investigation in most studies are of other types, instrumental, integrative, etc. Ignorance towards the relationship between these variables in one context can affect language teaching and learning processes negatively. Materials developers may feel dubious about designing culturally-bound materials, and language teachers might ignore working on both culture and intrinsic motivation in language classes.

\subsection{Null Hypotheses}

The following null hypotheses were proposed for this study:

H01: There is no relationship between Iranian EFL learners' cultural identity and pronunciation knowledge at intermediate level.

H02: There is no relationship between Iranian EFL learners' intrinsic motivation and pronunciation knowledge at intermediate level.

\section{Review of the Literature}

Literature on pronunciation teaching shows that there exists considerable emphasis on this pronunciation learning. This emphasis consists of two sections: understanding the significance of pronunciation learning and finding ways to increase pronunciation learning. For instance, Fraser (2000) noted that a good way to enhance teaching of pronunciation is to provide language teachers with courses on teaching pronunciation. Fraser (2000) also emphasized on the role of materials on teaching pronunciation; especially audio-based computer materials.

Morley (1991) confirmed that certain changes must be applied to enhance pronunciation teaching. The objective of teaching courses and the role of language teachers and learners should be changed. Teachers should coach pronunciation session and learners must take the initiative to learn. Super-segmental elements ought to be emphasized along with segmental elements. This is a practical approach to reach communicative competence through intelligible pronunciation. A common problem in language teaching curriculums, as stated by Elliott (1995) is that also a considerable deal of attention is paid to teaching pronunciation in primary stages of language teaching; when the alphabet and first words are presented to learners, this emphasis reduces in consequent years of language teaching and is replaced with emphasis on other aspects of language such as the reading or the writing skill. Elliott (1995) also asserts that in the view of many people, pronunciation learning is not significant; as a result, teaching pronunciation is sacrificed in language classes and other skills and sub-skills are practiced. Some factors seem to affect pronunciation learning which are discussed in this section.

Among the first variables is attitude. In some occasions language learners in a homogenous class seem to have varying paces in learning pronunciation. Some are more adept towards this issue and some are slower. Ellis (1995) believed that one of the principal variables affecting learning pronunciation is attitude. He observed this issue in learning both native language and non-native language pronunciation. Elliott (1995) concluded that the more language learners are concerned with this issue, the more accurate their pronunciation will be. These findings echoed Suter (1976) voice who also believed in such a relationship.

Some other factors determine whether or not a learner will have a native-like pronunciation. Among these variables motivation and culture are discussed. Language learners' professional goal for learning can influence their pronunciation (Masgoret \& Gardener, 2003), and motivates learners to have a native-like pronunciation (Bernaus, Masgoret, Gardner, \& Reyes, 2004). Marinova-Todd, Marshall and Snow (2000) believed that the factor determining whether adults can become proficient in native-like pronunciation or not is motivation. In addition Moyer (2007) stated that 2 factors determine developing native-like pronunciation. These factors are experience and motivation. Studies conducted with regard to other languages such as Spanish have come to the same conclusions. Shively (2008), for example, concluded that one of the main factors that develop good pronunciation in Spanish is encouraging language learners by the teachers. Finally, in the EFL context of Iran, studies that have considered cultural identity, intrinsic motivation and pronunciation knowledge are scant. Therefore, this study aims at filling in this gap.

\section{Method}

The researchers took a positivist stance in conducting this correlational study. Therefore, conclusions were made based on the observed data collected from the participants. Geertz (1965) theory of cultural ethnicity which viewed ethnicity as a consistent trait among people was among the main theories based on which this study was conducted. 
The participants for this study were selected among 74 language learners at Mahan Language Institute in Birjand, Iran. Forty three participants were selected non-randomly out of this population by administering Nelson language proficiency test. Although more participants could better serve the purpose of this study, only 43 language learners proved to be intermediate using Nelson proficiency test. This can be one of the limitations with regard to selecting the participants. The table below reveals participants demographic data.

Table 1. Participants Demographic Data

\begin{tabular}{llllll}
\hline $\mathrm{N}$ & Age & Gender & $\begin{array}{l}\text { Proficiency } \\
\text { Level }\end{array}$ & Religion & Ethnicity \\
\hline 49 & Adult (18 to 25) & Mixed & intermediate & Islam & Iranian \\
\hline
\end{tabular}

\subsection{Procedure}

This study began by administering consent forms to the participants. Next, Nelson language proficiency test was administered as the test of homogeneity based on which participants were selected out of the population of 74 language learners as intermediate learners $(n=49)$. One day after that, Mathews' Cultural Identity Questionnaire (2007) (as cited in Bazrafshan, 2015) was administered to the participants along with the intrinsic/extrinsic motivation questionnaire developed by Noels et al. (2000). On the third day of the study, all selected participants were interviewed using IELTS speaking test part 2. However, the only issue which was tested was language learners' pronunciation knowledge. Two raters with 5 years of experience were asked to score the recorded interviews.

\subsection{Instrumentation}

\subsubsection{Questionnaires}

The researchers, then, considered participants in 1 standard deviation above and below the mean score $(n=49)$. The results gained from these participants were used to further pursue the purpose of the study.

In the next phase of the study, 2 questionnaires were given to the participants. These questionnaires included: (a) Mathews' Cultural Identity Questionnaire (2007) and, (b) the intrinsic/extrinsic motivation questionnaire developed by Noels, Pelletier, Clement, and Vallerand (2000). The reliability of the questionnaires were measured using Crombach alpha and were $\alpha=0.71$ and $\alpha=.78$ for both questionnaires respectively.

\subsubsection{Pronunciation Learning Test}

The participants' pronunciation knowledge was gauged by two raters through an oral interview. Inter-rater reliability indices were checked between the raters to make sure the raters have inter-rater reliability. Table 2 shows the results of the inter-ratter reliability.

Table 2. Interclass Correlation Coefficient; Pronunciation Test

\begin{tabular}{lllllllll}
\hline & \multirow{2}{*}{$\begin{array}{l}\text { Interclass } \\
\text { Correlation }\end{array}$} & \multicolumn{2}{l}{$95 \%$ Confidence Interval } & \multicolumn{5}{l}{ F Test with True Value 0 } \\
\cline { 3 - 8 } & \cline { 4 - 8 } & Lower Bound & Upper Bound & Value & df1 & df2 & Sig \\
\hline Single Measures & .776 & .675 & .876 & 32.432 & 48 & 48 & .001 \\
Average Measures & .798 & .675 & .854 & 32.431 & 48 & 48 & .001 \\
\hline
\end{tabular}

As can be seen in Table 2, the results of inter-rater reliability ( $p=0.798, \alpha=001)$ reveal sufficient reliability in the way scores were measured.

\section{Results}

The data were tested for their normality before analysis. Table 3 reveals the results of normality tests.

Table 3. Normality test results

\begin{tabular}{lcccc}
\hline & \multicolumn{2}{c}{ Skewness } & \multicolumn{2}{c}{ Kurtosis } \\
\cline { 2 - 5 } & Statistic & Std. Error & Statistic & Std. Error \\
\hline Cultural Identity & .645 & .563 & .417 & .345 \\
\hline Intrinsic Motivation & .564 & .489 & .819 & .334 \\
\hline Pronunciation & .714 & .369 & .112 & .432 \\
\hline
\end{tabular}


As can be seen in Table 3, ratios of Skewness and Kurtosis are within the range of $+/-1.96$; thus, normal distribution of scores was assumed.

\subsection{Relationship between cultural identity and pronunciation knowledge}

H01: There is no relationship between Iranian EFL learners' cultural identity and pronunciation knowledge at intermediate level.

In order to test the first null hypothesis Pearson correlation was run between the results of the cultural identity questionnaire and the pronunciation scores.

Table 4 shows the results of Pearson correlation.

Table 4. Correlation between Cultural identity and Pronunciation Knowledge

\begin{tabular}{llr}
\hline & & Pronunciation \\
\hline Culture & Pearson Correlation & .034 \\
& Sig. (2-tailed) & .830 \\
& $\mathrm{~N}$ & 49 \\
\hline
\end{tabular}

As can be observed in Table 4, the results of Pearson Correlation (0.03) $\mathrm{p}=.830$ shows there is not a significant correlation between cultural identity and pronunciation knowledge of Iranian EFL learners, therefore, the first null hypothesis was supported.

\subsection{Relationship between intrinsic motivation and pronunciation knowledge}

H02: There is no relationship between Iranian EFL learners' intrinsic motivation and pronunciation knowledge.

In order to test the second null hypothesis Pearson correlation was run between intrinsic motivation results and pronunciation. Table 5 reveals the results of correlation between intrinsic motivation and pronunciation learning.

Table 5. Correlation between Intrinsic Motivation and Pronunciation

\begin{tabular}{llr}
\hline & & Pronunciation \\
\hline Intrinsic Motivation & Pearson Correlation & .84 \\
& Sig. (2-tailed) & .001 \\
\cline { 2 - 3 } & $\mathrm{N}$ & 43 \\
\hline
\end{tabular}

As can be noticed in Table 5, there is a significant correlation between intrinsic motivation and cultural identity; therefore the second null hypothesis was rejected.

\section{Discussion}

As it was revealed in the data analysis, there is a meaningful relationship between cultural intrinsic motivation and pronunciation learning of Iranian EFL learners whereas cultural identity and pronunciation knowledge did not have a significant correlation. Previous studies have, more or less, looked at the issues of identity, motivation and pronunciation leaning in the context of Iran (e.g., Bazrafshan, 2015; Yusofi \& Naderfarjad, 2015; Oroujlou \& Vahedi 2011; Banin Sheibani, 2012; Razmjoo \& Movahed, 2009). Having emphasized the significant of the relationship among identity, motivation and pronunciation learning in socio-cultural studies, the studies have looked at different aspects of this relationship which is discussed below.

Gardner's (1985) socio-cultural paved the way for researchers to investigate the interaction of variables such as identity, ethnicity, motivation, and language learning. This theoretical model has been used in the last 30 years by many scholars. Using this model, Razmjoo and Movahed (2009) believed that understanding the relationship between sociocultural factors and language learning is significant, as such factors could be predictors of language learning ability of the learners. In line with these researchers, Bazrafshan (2015) concluded that cultural identity and attitude can affect pronunciation learning of Iranian EFL learners. She examined 60 Iranian EFL learners studying at a high school in Iran, and concluded that cultural identity has a meaningful association with learning pronunciation among the Iranian EFL students. To make this conclusion, she referred to 9 items on Mathew's cultural identity questionnaire which dealt with pronunciation learning attitude; however, the findings of this study revealed that cultural identity does not have a significant relationship with pronunciation knowledge of Iranian EFL learners. It should be mentioned that the context of these two studies were rather different. Bazrafshan conducted her study at school, and this study was conducted in a language institute

A study was conducted by Oroujlou and Vahedi (2009) to find out whether there is any relationship between language learning, motivation and attitude in the EFL context of Iran. Although the researchers did not specify the type of 
motivation in the study, they concluded that such a relationship exist and making classroom techniques more interesting can change language learners' attitude toward pronunciation learning. In a different study, Yousofi and Nader Farjad (2015) conducted a study based on Gardners' socio-educational model of motivation. They endeavored to find any interaction between motivation with regard to integrativness and instrumentality and pronunciation skill of Iranian EFL learners. In accordance with Gardner and Tremblay (1994) and Banin Sheibani (2012), they concluded that these types of motivation are positively interrelated and affect pronunciation learning. Such a relationship was also witnessed in this study.

A divorce is observed between the studies conducted so far and the current study. Not only is literature on cultural identity and language learning very scant, but also the types of motivation investigated so far are mostly integrative and instrumental. The reason may be that previous studies have based themselves profoundly on Gardener's (1985) sociocultural model which focuses on the aforementioned types of motivation.

\section{Conclusion}

This study was an attempt to find out whether or not there is a relationship between cultural identity, intrinsic motivation, and pronunciation knowledge among Iranian EFL learners. The findings of the study revealed that although this relationship exists between intrinsic motivation and pronunciation knowledge, cultural identity and pronunciation knowledge have a negligible relationship. The results gained from this study can be useful to language teacher. Using these findings, they realize that more attention should be paid to intrinsic motivation of the learners to foster pronunciation learning among them. In addition, curriculum designers should add motivating the language learners to their educational objectives so that pronunciation knowledge of the language learners will be increased.

\section{References}

Ansarian, L., Adlipour, A. A., Saber, M. A., \& Shafiei, E. (2016). The Impact of Problem-Based Learning on Iranian EFL Learners' Speaking Proficiency. Advances in Language and Literary Studies, 7(3), 84-94.

Banin Sheibani, O. (2012). Language learning motivation among Iranian undergraduate students. World Applied Sciences Journal, 19(6), 838-846.

Bazrafshan, M. (2015). Cultural identity and attitudes: Iranian EFL context. Retrieved from http://semanticsarchive.net/Archive/mJiZDE2Y/bazrafshan1.pdf on 20.04.2017

Bernaus, M., Masgoret, A. M., Gardner, R. C., \& Reyes, E. (2004). Motivation and attitudes towards learning languages in multicultural classrooms. International Journal of Multilingualism, 1(2), 75-89.

Birdsong, D. (Ed.). (1999). Second language acquisition and the critical period hypothesis. Routledge.

Davoudi, M., \& Ramezani, H. (2014). The effects of cultural familiarity on reading comprehension of Iranian EFL learners. International Journal on Studies in English Language and Literature (IJSELL), 2(8), 58-71.

Dörnyei, Z. (1994). Motivation and motivating in the foreign language classroom. The modern language journal, 78(3), 273-284.

Dörnyei, Z. (2005). The psychology of the language learner. US: Lawrence Erlbaum Associates.

Elliott, A. R. (1995). Foreign language phonology: Field independence, attitude, and the success of formal instruction in Spanish pronunciation. The Modern Language Journal, 79(4), 530-542.

Ellis, R. (1995). Interpretation tasks for grammar teaching. TESOL Quarterly, 29(1), 87-105.

Ellis, R. (2008). Learner beliefs and language learning. Asian EFL Journal, 10(4), 7-25.

Fraser, H. (2000). Coordinating improvements in pronunciation teaching for adult learners of English as a second language. DETYA (ANTA Innovative project).

Gardner, R. C. (1985). Social psychology and second language learning: The role of attitudes and motivation. Arnold. Gardner, R. C., \& Tremblay, P. F. (1994). On motivation, research agendas, and theoretical frameworks. The Modern Language Journal, 78(3), 359-368.

Geertz, C. (1965). The impact of the concept of culture on the concept of man: In new views on the nature of man. USA: University Chicago Press.

Gilakjani, A. P., Sabouri, N. B., \& Zabihniaemran, A. (2015). What are the barriers in the use of computer technology in EFL instruction?. Review of European Studies, 7(11), 213.

Gonzales, R. D. (2010). Motivational orientation in foreign language learning: The case of Filipino foreign language learners. TESOL Journal, 3, 3-28

Lim, H. Y. (2002). The interaction of motivation, perception, and environment: One EFL learners' experience. Hong Kong Journal of Applied Linguistics, 7(2), 91-106.

Marinova-Todd, S. H., Marshall, D. B., \& Snow, C. E. (2000). Three misconceptions about age and L2 learning. TESOL quarterly, 34(1), 9-34. 
Masgoret, A. M., \& Gardner, R. C. (2003). Attitudes, motivation, and second language learning: a meta-analysis of studies conducted by Gardner and associates. Language learning, 53(1), 123-163.

Morley, J. (1991). The pronunciation component in teaching English to speakers of other languages. TESOL quarterly, 25(3), 481-520.

Moyer, A. (2007). Do language attitudes determine accent? A study of bilinguals in the USA. Journal of Multilingual and Multicultural Development, 28(6), 502-518.

Noels, K. A., Pelletier, L. G., Clément, R., \& Vallerand, R. J. (2000). Why are you learning a second language? Motivational orientations and self-determination theory. Language learning, 50(1), 57-85.

Norton, B. (2000). Identity and language learning: Gender, ethnicity and educational change. Editorial Dunken.

Oroujlou, N., \& Vahedi, M. (2011). Motivation, attitude, and language learning. Procedia-Social and Behavioral Sciences, 29, 994-1000.

Razmjoo, S. A., \& Movahed, M. (2009). On the Relationship between socio-cultural factors and language proficiency. Journal of Pan-Pacific Association of Applied Linguistics, 13(2), 59-76.

Shively, R. L. (2008). L2 acquisition of [[??]],[[??], and [[??]] in Spanish: Impact of experience, linguistic environment, and learner variables. Southwest Journal of Linguistics, 27(2), 79-115.

Smit, U. (2002). The interaction of motivation and achievement in advanced EFL pronunciation learners. IRAL, 40(2), 89-116.

Spackman, C. L. (2009). Culture and Second Language Acquisition. The Times.

Spada, N., \& Lightbown, P. M. (2008). Form-Focused Instruction: Isolated or Integrated? TESOL Quarterly, 42(2), 181-207.

Suter, R. W. (1976). Predictors of pronunciation accuracy in second language learning. Language Learning, 26(2), 233253.

Williams, M., \& Burden, R. L. (1997). Psychology for language teachers. Cambridge: Cambridge University Press.

Yousofi, N., \& Naderifarjad, Z. (2015). The Relationship between motivation and pronunciation: A case of Iranian EFL learners. Journal of Applied Linguistics and Language Research, 2(4), 249-262. 